\title{
Correction to: Bone mineral density in high-level endurance runners: part A-site-specific characteristics
}

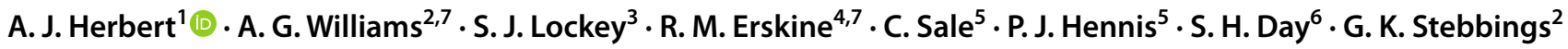

Published online: 19 October 2021

(c) The Author(s) 2021

\section{Correction to: European Journal of Applied Physiology https://doi.org/10.1007/s00421-021-04793-3}

The original version of this article unfortunately contained a mistake. Figure $1 \mathrm{C}$ was missing.
The corrected Fig. 1 should have appeared as shown in the following page.

The original article has been corrected.

The original article can be found online at https://doi.org/10.1007/ s00421-021-04793-3.

A. J. Herbert adam.herbert@bcu.ac.uk

1 School of Health Sciences, Birmingham City University, Birmingham, UK

2 Sports Genomics Laboratory, Department of Sport and Exercise Sciences, Manchester Metropolitan University, Manchester, UK

3 Faculty of Health, Education, Medicine and Social Care, Anglia Ruskin University, Chelmsford, UK

4 School of Sport and Exercise Science, Liverpool John Moores University, Liverpool, UK

5 Musculoskeletal Physiology Research Group, Sport, Health and Performance Enhancement Research Centre, School of Science and Technology, Nottingham Trent University, Nottingham, UK

6 School of Medicine and Clinical Practice, University of Wolverhampton, Wolverhampton, UK

7 Institute of Sport, Exercise and Health, University College London, London, UK 
Fig. 1 A Total bone mineral density $\left({ }_{\mathrm{T}} \mathrm{BMD}\right)$; $\mathbf{B}$ leg bone mineral density ( $\left.{ }_{L} B M D\right)$; and C lumbar spine bone mineral density $\left({ }_{L S} B M D\right)$ in male and female high-level endurance runners in relation to their calculated past bone-specific physical activity questionnaire (pBPAQ) score
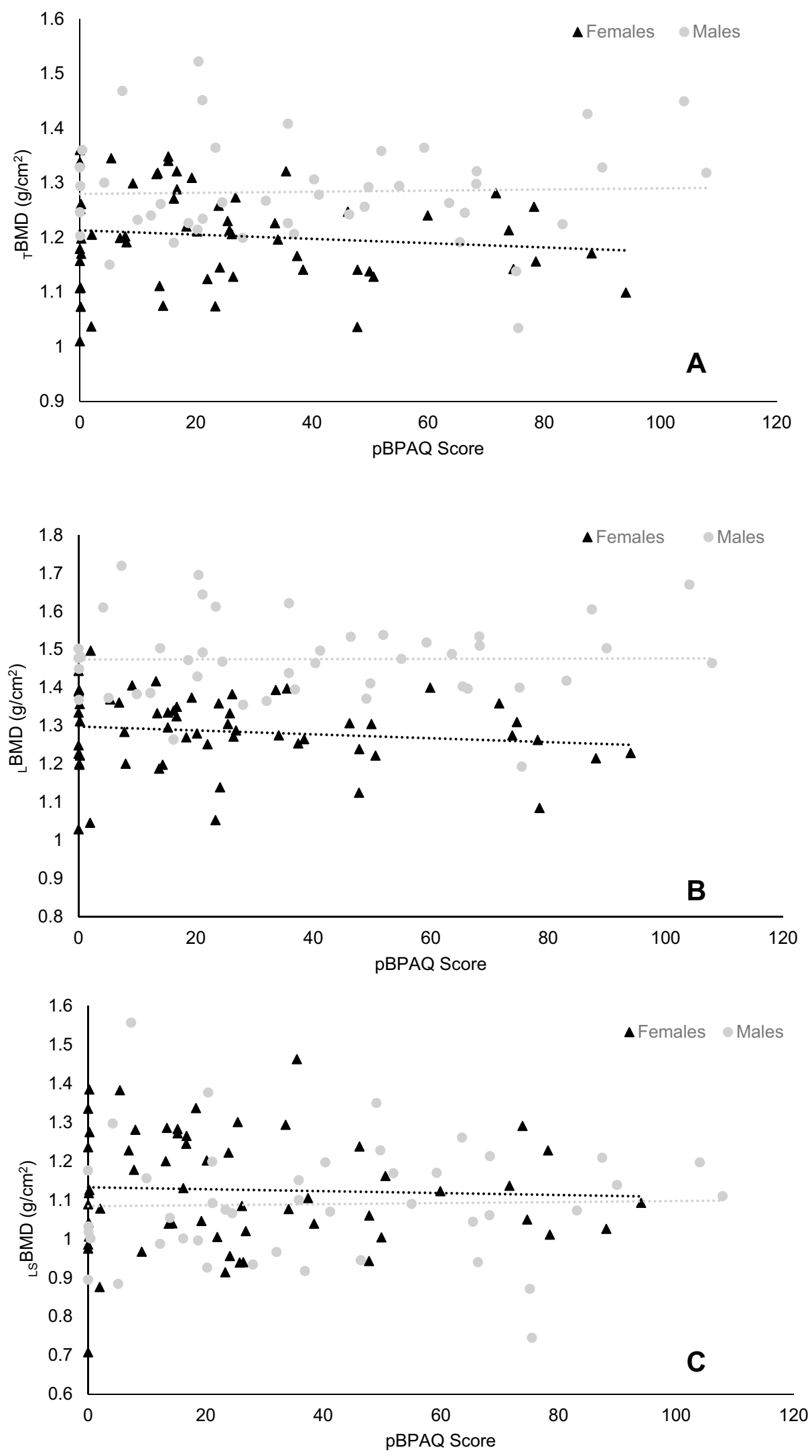
Open Access This article is licensed under a Creative Commons Attribution 4.0 International License, which permits use, sharing, adaptation, distribution and reproduction in any medium or format, as long as you give appropriate credit to the original author(s) and the source, provide a link to the Creative Commons licence, and indicate if changes were made. The images or other third party material in this article are included in the article's Creative Commons licence, unless indicated otherwise in a credit line to the material. If material is not included in the article's Creative Commons licence and your intended use is not permitted by statutory regulation or exceeds the permitted use, you will need to obtain permission directly from the copyright holder. To view a copy of this licence, visit http://creativecommons.org/licenses/by/4.0/.

Publisher's Note Springer Nature remains neutral with regard to jurisdictional claims in published maps and institutional affiliations. 